\title{
The role of building models in the evaluation of heat-related risks
}

\author{
Oliver Buchin $^{1}$, Britta Jänicke ${ }^{2}$, Fred Meier ${ }^{2}$, Dieter Scherer ${ }^{2}$, and Felix Ziegler ${ }^{1}$ \\ ${ }^{1}$ Institut für Energietechnik, Technische Universität Berlin, Berlin, Germany \\ ${ }^{2}$ Institut für Ökologie, Technische Universität Berlin, Berlin, Germany \\ Correspondence to: Oliver Buchin (oliver.buchin@tu-berlin.de)
}

Received: 23 October 2014 - Published in Nat. Hazards Earth Syst. Sci. Discuss.: 15 December 2014

Revised: 26 February 2016 - Accepted: 7 March 2016 - Published: 13 April 2016

\begin{abstract}
Hazard-risk relationships in epidemiological studies are generally based on the outdoor climate, despite the fact that most of humans' lifetime is spent indoors. By coupling indoor and outdoor climates with a building model, the risk concept developed can still be based on the outdoor conditions but also includes exposure to the indoor climate. The influence of non-linear building physics and the impact of air conditioning on heat-related risks can be assessed in a plausible manner using this risk concept.

For proof of concept, the proposed risk concept is compared to a traditional risk analysis. As an example, daily and city-wide mortality data of the age group 65 and older in Berlin, Germany, for the years 2001-2010 are used. Four building models with differing complexity are applied in a time-series regression analysis. This study shows that indoor hazard better explains the variability in the risk data compared to outdoor hazard, depending on the kind of building model. Simplified parameter models include the main nonlinear effects and are proposed for the time-series analysis. The concept shows that the definitions of heat events, lag days, and acclimatization in a traditional hazard-risk relationship are influenced by the characteristics of the prevailing building stock.
\end{abstract}

\section{Introduction}

Climate projections indicate that frequency, intensity, and duration of extreme heatwaves are likely to increase (Meehl, 2004; Field et al., 2012; Coumou and Robinson, 2013). The amplification of extreme temperatures due to the urban heat island effect can lead to elevated heat-related risks in urban areas (Oke, 1982; Giannaros et al., 2014; Gabriel and Endlicher, 2011).
Heat-related risk $r$ is defined as the likelihood of adverse effects (e.g. heat-related deaths or morbidity) on a specific system over a specified time period which can be associated to a hazardous heat event (Scherer et al., 2013). In general, a system is defined by its elements (e.g. a group of inhabitants) and its spatial distribution (e.g. country, city, or neighbourhood). Thus, risk is a mean intensity within a time span and within the spatial extent of the system group. It can be interpreted as the relation of the number of individuals with adverse effects $N_{\mathrm{a}}$ to the total number of individuals $N_{\text {tot }}$ of the system group:

$r=\frac{N_{\mathrm{a}}}{N_{\mathrm{tot}}}$.

All variables in this document are listed in Table 1. Additionally, disaster-risk analysis in accordance with the definitions proposed by the Intergovernmental Panel on Climate Change expresses risk $r$ as a product of hazard $h$ and vulnerability $v$ (Field et al., 2012):

$r=h v$.

A general risk approach like this differentiates between external driving processes measured in terms of hazard intensity $h$, and a system-specific vulnerability $v$ (Peduzzi et al., 2009; Scherer et al., 2013). Vulnerability is defined as the predisposition to be adversely affected and it includes the characteristics of anticipating, coping with, resisting, and recovering from the adverse effects as a result of diverse social, cultural, political, and institutional processes (Field et al., 2012).

The hazard intensity is calculated from an available climate signal, for instance a time series of air temperature measurements. According to the literature survey of Gosling et al. 
(2009a), many epidemiological approaches suggest a positive temperature deviation from a threshold temperature $T_{\mathrm{Th}}$ to be an appropriate functional relation to calculate a hazard intensity. A simple linear assumption can be implemented as follows:

$h=h\left(T, T_{\mathrm{Th}}\right)= \begin{cases}T-T_{\mathrm{Th}}, & \text { if } T-T_{\mathrm{Th}}>0 \\ 0, & \text { otherwise. }\end{cases}$

Many studies use linear or non-linear regression analyses of time series of hazard and risk data to quantify a temperature-risk relationship. The quantification and prediction of this relationship addresses different spatial scales: counties or regions (Knowlton et al., 2007; Armstrong et al., 2011; Sheridan et al., 2012; Zacharias et al., 2014; Wu et al., 2014), cities (Guest et al., 1999; Dessai, 2003; Gosling et al., 2009b; Peng et al., 2010), or wards (Rosenthal et al., 2014). Nonetheless, projections can only include modifiers that have been identified and calculated in an analysis based on past risk data. As the influence of buildings is not considered explicitly in the analyses it cannot be addressed in the projections. However, the influence of buildings on health is apparent as most people in midlatitude cities are subjected to indoor conditions more than $80 \%$ of the time, even during the summer season (Krause and Schulz, 1998; Jenkins et al., 1992). In particular, elderly people spend most of their time indoors at home (Brasche and Bischof, 2005). Furthermore, the nightly process of physiologic regeneration is considered very important to reduce heat stress, and it is therefore necessary to consider the indoor environment in the risk assessment (Franck et al., 2013; Wright et al., 2005).

Risk evaluations which consider buildings are often based on case-control studies during specific heat events. For example, a statistically significant relation of increased mortality for residents in top-floor apartments and reduced risk for people with access to air conditioning is documented for the 1995 heatwave in Chicago (Semenza et al., 1996). Increased mortality for the 2003 heatwave in France is shown for people living in buildings built prior to 1975 , and for buildings with poor insulation and high proportion of translucent building surface (Vandentorren et al., 2006; Salagnac, 2007). Reduced heatstroke risks could be statistically attributed to access to air conditioning (Kilbourne et al., 1982). The longterm decline in heat-related mortality in 19 out of 28 cities in the United States is primarily attributed to increased access to air conditioning (Davis et al., 2003). Similarly, disparities by race in heat-related mortality in four US cities for the years 1986 to 1993 could be attributed to differences in central air-conditioning prevalence (O'Neill et al., 2005). Buildingrelated proxies can be considered in a principal component analysis (Wolf and McGregor, 2013); however, the underlying linearization cannot reflect the non-linear effect of buildings.

Numerous studies have evaluated the overheating risk of building types and the impact of building-related countermeasures to overheating (e.g. Jenkins et al., 2011; Porritt
Table 1. Variables and indices. (Example units which are consistent to the proof-of-concept analysis are indicated with *.)

\begin{tabular}{|c|c|c|}
\hline Variable & Unit & Description \\
\hline$a$ & {$[-]$} & $\begin{array}{l}\text { fraction of individuals in air- } \\
\text { conditioned environments }\end{array}$ \\
\hline$b_{i}$ & & model parameters \\
\hline$c$ & {$[-]$} & coefficient \\
\hline$C$ & $\mathrm{~J} \mathrm{~K}^{-1}$ & thermal capacity \\
\hline$e$ & {$[-]$} & exposure \\
\hline$g$ & $\mathrm{~m}^{2}$ & transmittance of radiation \\
\hline$h$ & $\mathrm{~K}$ & hazard* \\
\hline$\dot{I}$ & $\mathrm{~W} \mathrm{~m}^{-2}$ & global horizontal short-wave irradiation \\
\hline$k_{i}$ & & model parameters \\
\hline$N$ & {$[-]$} & number of individuals \\
\hline$\dot{Q}$ & W & internal heat sources \\
\hline$r$ & $a^{-1}$ & risk $^{*}$ \\
\hline$R$ & $\mathrm{~K} \mathrm{~W}^{-1}$ & building envelope resistance \\
\hline$t$ & s & time \\
\hline$T$ & & temperature \\
\hline$v$ & $\mathrm{a}^{-1} \mathrm{~K}^{-1}$ & vulnerability* \\
\hline$\alpha$ & & model parameter \\
\hline$\lambda$ & $\mathrm{K} \mathrm{m}^{2} \mathrm{~W}^{-1}$ & solar temperature elevation constant \\
\hline$\tau$ & s & time constant \\
\hline Indices & & Description \\
\hline 0 & & base value \\
\hline $\mathrm{a}$ & & adverse \\
\hline ac & & air-conditioned \\
\hline heat & & heating set point \\
\hline hist & & historic \\
\hline in & & indoor \\
\hline out & & outdoor \\
\hline Th & & threshold \\
\hline tot & & total \\
\hline uc & & non-air-conditioned \\
\hline
\end{tabular}

et al., 2012; Beizaee et al., 2013; Ji et al., 2014; Mavrogianni et al., 2014). Nonetheless, the overheating risk, which is often defined as deviation from a thermal comfort index, cannot be easily related to the heat-related health risk, as analyses operate with different scales and threshold values.

Despite the qualitative and quantitative evidence for the influence of the building parameters and air conditioning on the heat-related risks, these are not covered systematically in epidemiological analysis of time-series data and thus cannot be implemented in reliable projections. Despite singular studies which have evaluated indoor-climate risk relationships (Brandt, 2006), developed building-type-related vulnerability indices (Wolf and McGregor, 2013), or which have addressed the practicability of a building model for heat-health warning (Pfafferott and Becker, 2008), a conceptual framework is missing.

The objective of this study is the development of a risk concept which considers building physics and indoor climate conditions. This risk concept extends typical epidemiological 
approaches and is developed within Research Unit 1736, Urban Climate and Heat Stress in midlatitude cities in view of climate change (UCaHS). The study aims to provide a simple yet accurate concept to include the physical aspects of buildings in heat-related risk analysis which can be easily applied to typical epidemiological approaches with spatially integrated risk data. Four different building models that vary in their complexity are evaluated with regard to their applicability in such a concept. The indoor concept is tested with a time series of mortality data of the age group 65 and older in Berlin, Germany, for the years 2001 to 2010. Finally, the definitions of heat events, lag, and acclimatization in existing risk analyses are discussed within this conceptual framework.

\section{Methods and materials}

\subsection{Indoor/outdoor risk concept}

In an established risk evaluation the hazard is based on the outdoor climate only. Nonetheless, many persons at risk are subjected to indoor conditions, which might be dependent on the outdoor climate but can also be independent from the outdoor conditions by means of air conditioning. Following this argumentation, an appropriate risk concept must differentiate between indoor and outdoor hazard. Defining exposure $e$ as the degree of exposure to either indoor or outdoor hazard, we derive the equation:

$h=e h_{\text {out }}+(1-e) h_{\text {in }}$.

Exposure $e$ in our understanding describes the ratio of the number of individuals in the group exposed to the outdoor climate $N_{\text {out }}$ to the total number of individuals in the group $N_{\text {tot: }}$ :

$e=\frac{N_{\text {out }}}{N_{\text {tot }}}$.

Exposure $e$ varies between 0 and 1 with $e=1$ meaning that the system group is exposed to the outdoor hazard only, whilst $e=0$ describes the full exposure to the indoor hazard.

Note that some studies on disaster-risk assessment include an exposure term $e$ as a third factor in Eq. (2) (Field et al., 2012). This term covers the degree of exposure of the group under consideration to the hazardous process. However, a clear definition of the hazard event has to be available to calculate exposure from the climate data.

The fraction of individuals in air-conditioned environments $N_{\text {in,ac }}$ to the total number of individuals indoors $N_{\text {in }}$ is introduced by an air-conditioning ratio $a$ :

$a=\frac{N_{\text {in }, \mathrm{ac}}}{N_{\text {in }}}$.

The indoor hazard $h_{\text {in }}$ is calculated as a mean of the hazard $h_{\text {in, ac }}$ for air-conditioned environments and the hazard $h_{\text {in,uc }}$ for non-air-conditioned environments, weighted with the fraction of individuals in air-conditioned environments $a$ and in non-air-conditioned environments $(1-a)$ :

$h_{\text {in }}=a h_{\text {in }, \mathrm{ac}}+(1-a) h_{\text {in, uc }}$.

Obviously, air-conditioned indoor environments, which are predominantly conditioned according to common comfort criteria, do not impose a heat-stress hazard $\left(h_{\mathrm{in}, \mathrm{ac}}=0\right)$. With this assumption, Eqs. (4), (7), and (2) yield:

$r=\left(e h_{\text {out }}+(1-a)(1-e) h_{\text {in }}\right) v$.

\subsection{Simplified indoor/outdoor risk concept}

To compare the general risk concept (Eq. 2) and the indoor/outdoor risk concept (Eq. 8) on a theoretical level, it is useful to assume a linear correlation between indoor and outdoor hazard, $h_{\text {in }}=c h_{\text {out }}$. We can rearrange Eq. (8), with parameter $c$ describing the outdoor hazard transformation by the building stock:

$r=h_{\text {out }}((1-a)(1-e) c+e) v$.

We can interpret the term $((1-a)(1-e) c+e) v$ as a modified vulnerability in the traditional risk analysis or the term $h_{\text {out }}((1-a)(1-e) c+e)$ as a modified hazard, arbitrarily. Both interpretations are consistent with the general framework of Eq. (2) as only a constant factor is multiplied. However, the simplified indoor/outdoor risk concept fails if the assumption of linearity between indoor and outdoor hazard is not fulfilled. Conditions with indoor hazard but no outdoor hazard, e.g. elevated indoor temperatures in glazed rooms with high internal loads, or vice versa, obviously contradict linearity. Therefore it is important to study the non-linear influence of buildings on the hazard-risk relationship in particular.

\subsection{Building models}

Long-term observations of indoor environments in order to quantify the indoor hazard are normally not available. Thus, the indoor conditions have to be evaluated with simulation data of modelled buildings. To allow for a risk evaluation with a reduced set of weather data (e.g. air temperature), simplified building models were evaluated in this study. We used a complex building model (EnergyPlus) to simulate a representative indoor climate and to parametrize three simplified building models. The three building models are based on either a linear relation between indoor and outdoor temperatures (linear building model), the analytical solution of a simplified capacity-resistance-transmittance model (physical building model), or a recursive modelling approach (recursive building model). We used these models to simulate the indoor temperature with a restricted climate data set.

\subsubsection{EnergyPlus building model}

Sophisticated building models are based on energy balances of building components and zones. As the models cannot be 
solved analytically, numerical solvers are used. We use EnergyPlus energy simulation software (EnergyPlus, 2015, version 8.3) to model a representative building. This software is widely used for building simulations, also in overheating studies (Porritt et al., 2012; Mavrogianni et al., 2014). The main physical processes, namely heat conduction, convection, infiltration, shading, and solar radiation, as well as occupant behaviour are considered. More details on the model setup and specific parametrization are provided in Sect. 2.3.5 and in the model description file (EnergyPlus idf format) which is provided in the Supplement. The simulation results of this model (operative room temperatures) are used for risk analysis and to parametrize the simplified building models described in the following subsections.

\subsubsection{Linear building model}

A simple quasi-linear approach with two coefficients $k_{1}$ and $k_{2}$ can be used to calculate a time series of daily mean indoor temperatures $T_{\text {in }}(t)$ from daily mean outdoor temperatures $T_{\text {out }}(t)$ :

$T_{\text {in }}(t)=\max \left(k_{1} T_{\text {out }}(t)+k_{2} ; T_{\text {heat }}\right)$.

For the cold season it can be assumed that the indoor temperature in the building does not fall below a minimum temperature $T_{\text {heat }}$, which is controlled by the heating system. Despite the expected deviations, we used the linear model to foster understanding of the indirect influence of buildings in a traditional temperature-risk analysis with linear approaches (e.g. analysis of variance with multivariate linear regression or principal component analysis).

\subsubsection{Physical building model}

We can interpret the indoor climate as a function of the outdoor climate, the functional relation being described by the building parameters. A very simple one-zonal energybalance model of the building (or room) can be solved analytically:

$C \frac{\mathrm{d} T_{\text {in }}(t)}{\mathrm{d} t}=\frac{1}{R}\left[T_{\text {out }}(t)-T_{\text {in }}(t)\right]+g \dot{I}(t)+\dot{Q}(t)$.

Equation (11) is an inhomogeneous first-order differential equation with thermal capacity $C\left[\mathrm{JK}^{-1}\right]$, building envelope resistance $R\left[\mathrm{KW}^{-1}\right]$, transmittance of radiation $g\left[\mathrm{~m}^{2}\right]$, and internal heat source $\dot{Q}$. Ventilation is neglected in this model. Assuming constant outdoor climate conditions and a constant heat source during the time step $\Delta t$ (indicated with the caret grapheme), the analytical solution of Eq. (11) for the indoor temperature yields

$$
\begin{aligned}
& T_{\text {in }}(t+\Delta t)=\widehat{T}_{\text {out }}+\lambda \widehat{\dot{I}}+R \widehat{\dot{Q}} \\
& +\left(T_{\text {in }}(t)-\widehat{T}_{\text {out }}-\lambda \widehat{\dot{I}}-R \widehat{\dot{Q}}\right) e^{-\Delta t / \tau} .
\end{aligned}
$$

The remaining parameters characterizing the building are $\tau=R C$ and $\lambda=g R . \tau$ represents a time constant as a mea- sure for the thermal inertia of the building, $\lambda$ represents the temperature elevation due to solar gains. $T_{\text {in }}(t)$ is the initial indoor temperature at time $t$ for the time interval $\Delta t$.

For the cold season, a constant temperature $T_{\text {heat }}$ is used with the same reason as for the linear building model. For the warm season we assume that internal heat sources are negligible compared to the solar heat flux into the zone. With these assumptions, Eq. (12) can be simplified:

$$
\begin{aligned}
& T_{\text {in }}(t+\Delta t)=\max \left(\widehat{T}_{\text {out }}+\lambda \widehat{\dot{I}}\right. \\
& \left.+\left(T_{\text {in }}(t)-\widehat{T}_{\text {out }}-\lambda \widehat{\dot{I}}\right) e^{-\Delta t / \tau} ; T_{\text {heat }}\right) .
\end{aligned}
$$

We used this model to simulate the hourly indoor temperature with a restricted climate data set, which consists of only outdoor air temperature and global horizontal radiation. For risk analysis daily mean temperatures are calculated from the hourly values.

\subsubsection{Recursive building model}

A simple recursive model was developed by Wright et al. (2005) to cover the thermal inertia of a building structure:

$T_{\text {in }}=\max \left(b_{1} T_{\text {hist }}+b_{2} ; T_{\text {heat }}\right)$.

$T_{\text {hist }}(t+\Delta t)=\alpha T_{\text {out }}(t+\Delta t)+(1-\alpha) T_{\text {hist }}(t)$.

This model is similar to the physical model for constant time steps and when $b_{1}=1$. In this case, the parameter $\alpha$ represents the thermal inertia, and parameter $b_{2}$ includes the temperature elevation due to constant internal loads. This model is only based on daily mean outdoor temperatures and does not explicitly include solar irradiation. We used this model to evaluate the applicability of daily mean outdoor air temperature as one single climate datum in the indoor/outdoor risk concept.

\subsubsection{Parametrization data}

Typically, a hazard is defined as an integral value for a spatially confined system. Therefore, the building model has to be representative for the same system. The modelled building represents a typical Berlin residential building of the era of promoterism and Art Nouveau block development from 1870 to 1918 (see Fig. 1). This building type is the most prevalent type in the Berlin building stock (SDUD, 2011) and it is inhabited by approximately one-third of the Berlin population (see Table 2).

This building type is implemented for one specific construction in EnergyPlus with typology data from IWU (2011, code DE.N.AB.02.Gen). The building geometry was simplified with regard to window partitioning and the presence of balconies and oriels. See Fig. 1 for the implemented example's zone structure. Technical specifications were extracted from the building typology and implemented in the EnergyPlus model (see Table 3). The typical shading in urban areas by other buildings was implemented in the domain of the 
model. The minimum indoor temperature for heating is assumed to be $T_{\text {heat }}=20^{\circ} \mathrm{C}$ (DIN EN 12831:2008-07).

The building simulation includes infiltration, which depends on wind speed and the air temperature difference between the inner zone and the outside (EnergyPlus, 2015, ZoneInfiltration: DesignFlowRate). To model adaptive occupant behaviour with increased window opening during the summertime, base infiltration rates are set threefold for the summer season compared to the winter season. Furthermore, a window shading algorithm is implemented to include the moderate effect of closed curtains or comparable shading devices in the summer. The implemented algorithms model a moderate adaptation by the occupants and thus can be considered representative of the Berlin housing stock.

\subsection{Climate data}

We used a set of weather data (air temperature, humidity, atmospheric pressure, wind velocity, wind direction, diffuse and direct horizontal short-wave radiation) from Potsdam, $\sim 25 \mathrm{~km}$ from the centre of Berlin, for the time period 2001 to 2010 (DWD, 2014). Missing data of atmospheric pressure $(0.02 \%)$, wind direction $(0.42 \%)$, and wind velocity $(0.0046 \%)$ were filled with linearly interpolated values. Missing data of global horizontal short-wave radiation $(0.51 \%)$ were filled with regressed radiation data from a weather station operated by Technische Universität Berlin in Berlin Steglitz (Fenner et al., 2014). Missing data of diffuse short-wave radiation $(0.79 \%)$ were filled with simulated data according to a correlation with the global horizontal shortwave radiation proposed by Erbs et al. (1982). Finally, the consistent data set was transformed into an EnergyPlus conform weather file.

\subsection{Risk data}

The age-classified number of deaths (all-cause deaths) in Berlin in daily resolution and half-yearly population data serve as the basis to calculate all-cause mortality rates. The population data are interpolated to daily resolution. Both data sets are valid for the group of people aged 65 and older and for the period 1 January 2001 to 31 December 2010 (SOBB, 2013). This age group can be assumed to be fully exposed to the indoor climate $(e=0)$ as the mean time spent at home is over $80 \%$ (Brasche and Bischof, 2005). Furthermore, it can be assumed that air conditioning is not prevalent in Berlin $(a=0)$.

The risk data for temperatures below the threshold temperature are used to calculate a constant base rate of the risk $r_{0}$. With this segmented approach it is possible to obtain a consistent structuring of the risk data into heat-affected and heatunaffected risks. The total risk calculates to

$r_{\text {tot }}= \begin{cases}r_{0}+h_{\mathrm{in}} v, & \text { if } h_{\mathrm{in}}>0 \\ r_{0}, & \text { otherwise. }\end{cases}$
The risk data and an example regression result with operative room temperatures from the EnergyPlus model and a threshold temperature of $28^{\circ} \mathrm{C}$ are shown in Fig. 6. It can be seen that mortality rates are increased in the winter season at operative room temperatures below $20^{\circ} \mathrm{C}$ which can be associated with indirect climate effects involving influenza and respiratory infections (Kunst et al., 1993).

\section{Analysis}

\subsection{Parametrization of the simple building models}

Simulation results of the mean daily operative room temperature of an intermediate thermal zone (second-floor, westoriented) of the EnergyPlus building model are used for parametrization of the linear, physical, and recursive building model with a trust region method (Matlab lsqcurvefit algorithm). One intermediate floor was used as it can be considered to represent the mean climate in the whole building.

Parametrization of the simple building models yields $k_{1}=$ 0.63 and $k_{2}=12.0 \mathrm{~K}$ for the linear model, $\tau=4.115 \cdot 10^{5} \mathrm{~s}$ and $\lambda=0.025 \mathrm{~m}^{2} \mathrm{KW}^{-1}$ for the physical model, and $b_{1}=$ $0.96, b_{2}=6.6 \mathrm{~K}$, and $\alpha=0.28$ for the recursive model.

The resulting indoor temperatures are plotted for July 2007 in Fig. 2 together with the outdoor air temperatures which fluctuate with an amplitude of about $10 \mathrm{~K}$. The EnergyPlus simulation generates pronounced diurnal temperature variations of 2 to $4 \mathrm{~K}$ and the general trend follows the outdoor air temperatures with a lag of several days. Indoor night-time temperatures do not fall below $20^{\circ} \mathrm{C}$. All simplified models can reproduce the general trend; however, the thermal lag cannot be reproduced with the linear model. The physical model is able to generate diurnal variations, albeit with lower amplitude than the results from the EnergyPlus simulation. The recursive model and linear model are based on daily mean temperatures and therefore cannot reproduce the diurnal variation.

Figure 3 shows the daily mean indoor temperature from the simulations with the EnergyPlus model and the linear model plotted against the outdoor air temperature. The linear building model reproduces the general trend of the detailed simulation data. However, maximum deviations may be almost $5 \mathrm{~K}$, as can be seen in a scatter plot of the indoor temperatures from the linear model against the temperatures calculated with the EnergyPlus building model (Fig. 4). The root mean square deviation (RMSD) is $1.5 \mathrm{~K}$. Normalization with the overall temperature span yields a normalized RMSD of $12.2 \%$. The physical approach reproduces the data with a RMSD of $0.61 \mathrm{~K}$ and a normalized RMSD of $5.0 \%$. The recursive building approach yields a RMSD of $0.77 \mathrm{~K}$ and a normalized RMSD of $6.3 \%$.

We can therefore conclude that the simple physical building model is best suited to calculate daily mean indoor temperatures. If no data on solar radiation are available, the re- 

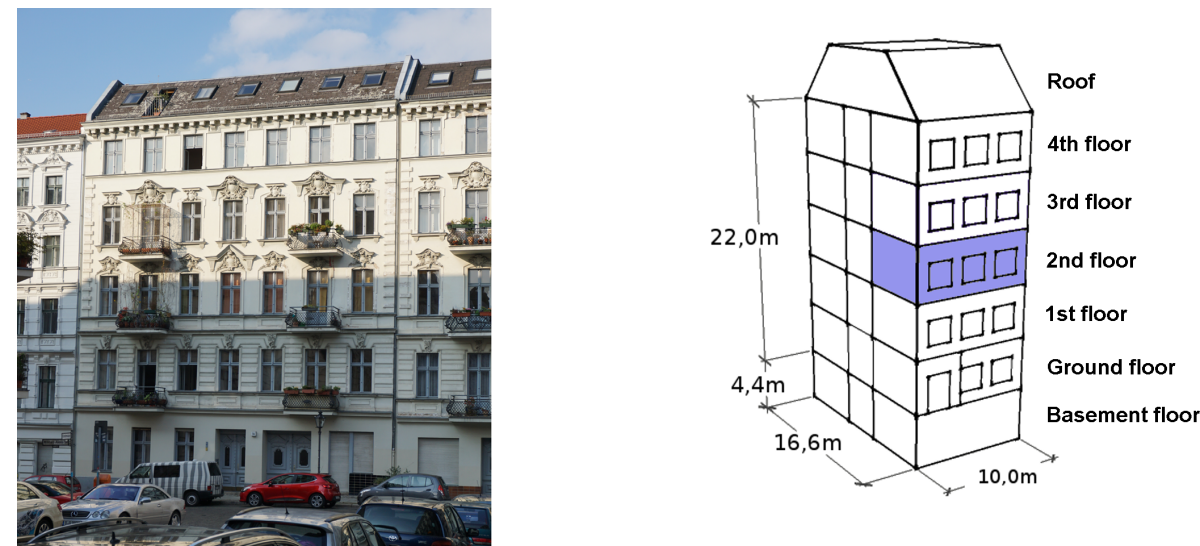

Figure 1. Typical residential building in Berlin (left) and graphical representation of the geometry of the EnergyPlus model (right). The analysis zone in the second floor is marked-up.

Table 2. Building structures and construction periods in Berlin and number of inhabitants calculated with mean population density and area according to planning area typology (SDUD, 2011).

\begin{tabular}{lllcr}
\hline Construction period & Building structures & Area (ha) & Inhabitants & Percentage \\
\hline $1870-1918$ & block-type structures, four to six storeys & 2888 & 965000 & $28.3 \%$ \\
$1870-1918+$ newer & block-type structures, space closure & 1124 & 298000 & $8.7 \%$ \\
$1920-1930$ & block-type structures with large courtyards & 779 & 132000 & $3.9 \%$ \\
$1920-1940$ & parallel, oriented line-type structures & 853 & 221000 & $6.5 \%$ \\
$1950-1980$ & line-type structures & 2540 & 414000 & $12.1 \%$ \\
$1960-1990$ & high-rise buildings and greater settlements & 2283 & 632000 & $18.5 \%$ \\
$1990-$ today & mixed types & 515 & 107000 & $3.1 \%$ \\
all periods & detached houses & 14702 & 643000 & $18.8 \%$ \\
\hline
\end{tabular}

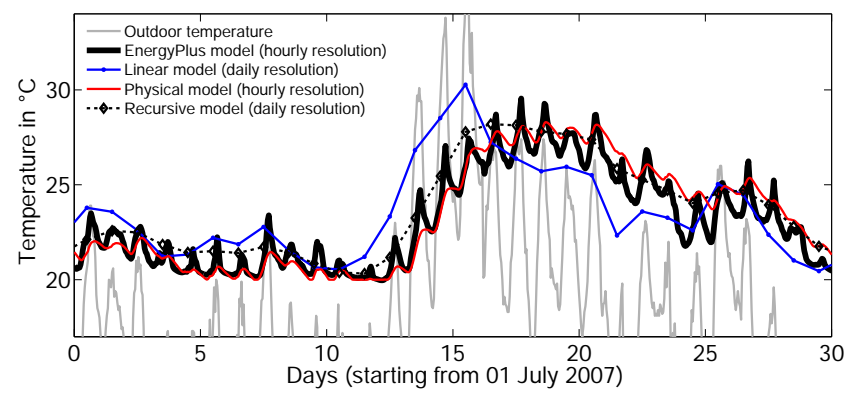

Figure 2. Outdoor air temperature and indoor temperatures for July 2007 calculated from building models parametrized according to Sec. 3.1.

cursive model is also suitable to recalculate the indoor temperatures. A linear relation as in the linear model should be avoided because it would incorporate higher deviations as thermal inertia and solar gains are not covered. All calculated time series of the indoor temperatures were used in the following risk analysis section.

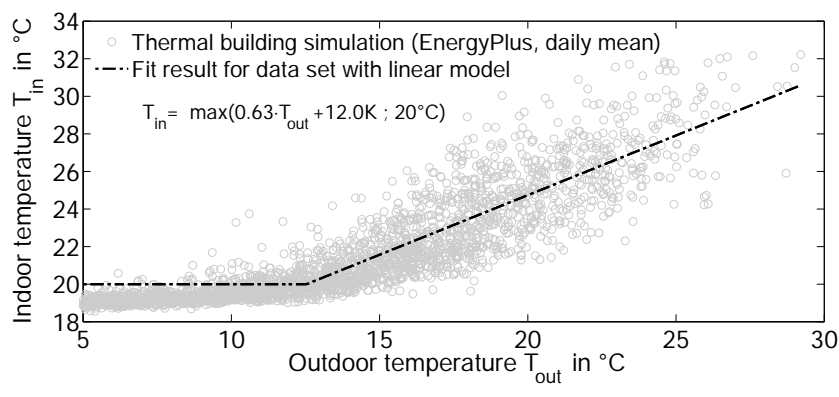

Figure 3. Linear building model (Eq. 10) fitted to mean daily operative room temperature of a typical residential building of Berlin simulated with EnergyPlus.

\subsection{Qualitative risk analysis}

For qualitative evaluation the risk data is plotted against the different hazard signals, namely outdoor air temperature and indoor operative room temperatures calculated from the EnergyPlus simulation and the three simplified building models (Fig. 5). Additionally, arithmetic mean values of the mortality rates are given for a $1 \mathrm{~K}$ interval to extract the general trend. 
Table 3. Basic assumptions for the implementation of a Berlin residential building from the construction period 1860 to 1918 in the EnergyPlus model (in accordance with IWU, 2011, code DE.N.AB.02.Gen).

\begin{tabular}{|c|c|}
\hline Component & Specification \\
\hline General & $\begin{array}{l}\text { apartment block, five storeys, gable roof, wooden beam ceiling, solid brick masonry, } \\
\text { heated area } 754 \mathrm{~m}^{2} \text {, adiabatic south-oriented and north-oriented walls, } \\
\text { partial shading by other buildings, curtains closed above } 24^{\circ} \mathrm{C} \text { with solar transmittance }=0.8 \text {, } \\
\text { inner loads }=5 \mathrm{Wm}^{-2} \text {, infiltration (cooling season) }=2 \mathrm{~h}^{-1} \cdot\left(0.01 \Delta T \mathrm{~K}^{-1}+0.02 v \mathrm{sm}^{-1}\right)\end{array}$ \\
\hline Floor (basement) & $U$ value $=0.9 \mathrm{~W} \mathrm{~m}^{-2} \mathrm{~K}^{-1}, \lambda_{\text {th }}=1.55 \mathrm{~W} \mathrm{~m}^{-1} \mathrm{~K}^{-1}, \rho=2000 \mathrm{~kg} \mathrm{~m}^{-3}, c_{\mathrm{p}}=840 \mathrm{~J} \mathrm{~kg}^{-1} \mathrm{~K}^{-1}$ \\
\hline Windows & $U$ value $=3.5 \mathrm{~W} \mathrm{~m}^{-2} \mathrm{~K}^{-1}, g$ value $=0.8$ \\
\hline Outer masonry & $U$ value $=1.7 \mathrm{~W} \mathrm{~m}^{-2} \mathrm{~K}^{-1}, \lambda_{\mathrm{th}}=0.96 \mathrm{~W} \mathrm{~m}^{-1} \mathrm{~K}^{-1}, \rho=2000 \mathrm{~kg} \mathrm{~m}^{-3}, c_{\mathrm{p}}=840 \mathrm{~J} \mathrm{~kg}^{-1} \mathrm{~K}^{-1}$ \\
\hline Inner masonry & $d=0.3 \mathrm{~m}, \lambda_{\mathrm{th}}=0.96 \mathrm{~W} \mathrm{~m}^{-1} \mathrm{~K}^{-1}, \rho=2000 \mathrm{~kg} \mathrm{~m}^{-3}, c_{\mathrm{p}}=840 \mathrm{Jkg}^{-1} \mathrm{~K}^{-1}$ \\
\hline Roof & $U$ value $=1.3 \mathrm{~W} \mathrm{~m}^{-2} \mathrm{~K}^{-1}$ \\
\hline
\end{tabular}

$d$ denotes thickness, $\lambda_{\text {th }}$ thermal conductivity, $\rho$ density, $c_{\mathrm{p}}$ specific heat, $v$ wind speed.

The analysis shows that a correlation with the outdoor air temperature (Fig. 5, top left) predicts unchanged mortality rates in a temperature range from 16 to $20^{\circ} \mathrm{C}$ and a steady increase above $20^{\circ} \mathrm{C}$. At highest temperatures $\left(>27^{\circ} \mathrm{C}\right)$, the signal for rising mortality rates is less accurate and arithmetic mean mortality rates within a $1 \mathrm{~K}$ interval are fluctuating, due to a low number of heat events. The highest mortality rates can be observed in the temperature region around $24^{\circ} \mathrm{C}$ and therefore do not correspond to the highest values of the hazard signal. Elevated mortality rates of the winter season are not relevant for this study and only influence mortality rates at outdoor air temperatures lower than $15^{\circ} \mathrm{C}$ (not shown in this graph).

When evaluating the same risk data with indoor temperatures from the linear building model (Fig. 5, top right), due to the linear transformation no qualitative change in the data compared to the outdoor climate approach is observed. Note that elevated mortality rates occur at about $20^{\circ} \mathrm{C}$ due to the influence of the winter season data.

Using indoor temperatures from the EnergyPlus simulation, it can be observed that mortality rates increase at indoor temperatures higher than $25^{\circ} \mathrm{C}$ (Fig. 5, middle). A further increase can be detected above $30^{\circ} \mathrm{C}$. A similar structure of the data is obtained with the physical and recursive building models (Fig. 5, bottom). The arithmetic mean mortality rates within $1 \mathrm{~K}$ intervals are not as steady in the recursive approach as in the physical approach. The highest mortality rates can be observed at the highest hazard signals for all non-linear building models.

\subsection{Quantitative risk analysis}

In a quantitative regression analysis, the coefficient of determination $R^{2}$ for the linear least-squares regression of temperature and risk above the threshold value was evaluated for all four approaches using Eq. (8). $R^{2}$ is the proportion of the total sum of squares that is explained by the riskhazard relationship according to Eq. (16) in the heat-affected

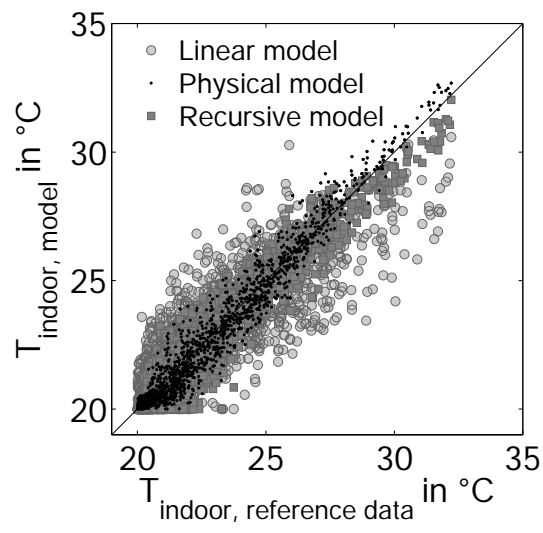

Figure 4. Calculated mean daily indoor temperature of parametrized linear, physical, and recursive building models according to Sec. 3.1 compared to the EnergyPlus simulation results.

region. The hazard was calculated according to Eq. (3) with threshold temperatures in the range of 16 to $30^{\circ} \mathrm{C}$ for outdoor air temperatures and 21 to $33^{\circ} \mathrm{C}$ for indoor temperatures. Furthermore, the relative standard deviation of the estimated vulnerability was calculated. Risk data for outdoor air temperatures exceeding $16^{\circ} \mathrm{C}$ and for indoor temperatures exceeding $21^{\circ} \mathrm{C}$ were used, as data points at lower temperatures might be influenced by cold-related risk effects. Only threshold temperatures were evaluated which separate heataffected and heat-unaffected risk data according to their median values with high statistical significance. The null hypothesis that data below and above the threshold temperature are independent samples from identical continuous distributions with equal medians had to be rejected with a Wilcoxon rank sum test at a $1 \%$ significance level.

We followed a segmented regression approach. Firstly, the base rate of the risk $r_{o}$ was calculated from the heatunaffected data (see also Fig. 6) below the threshold tem- 

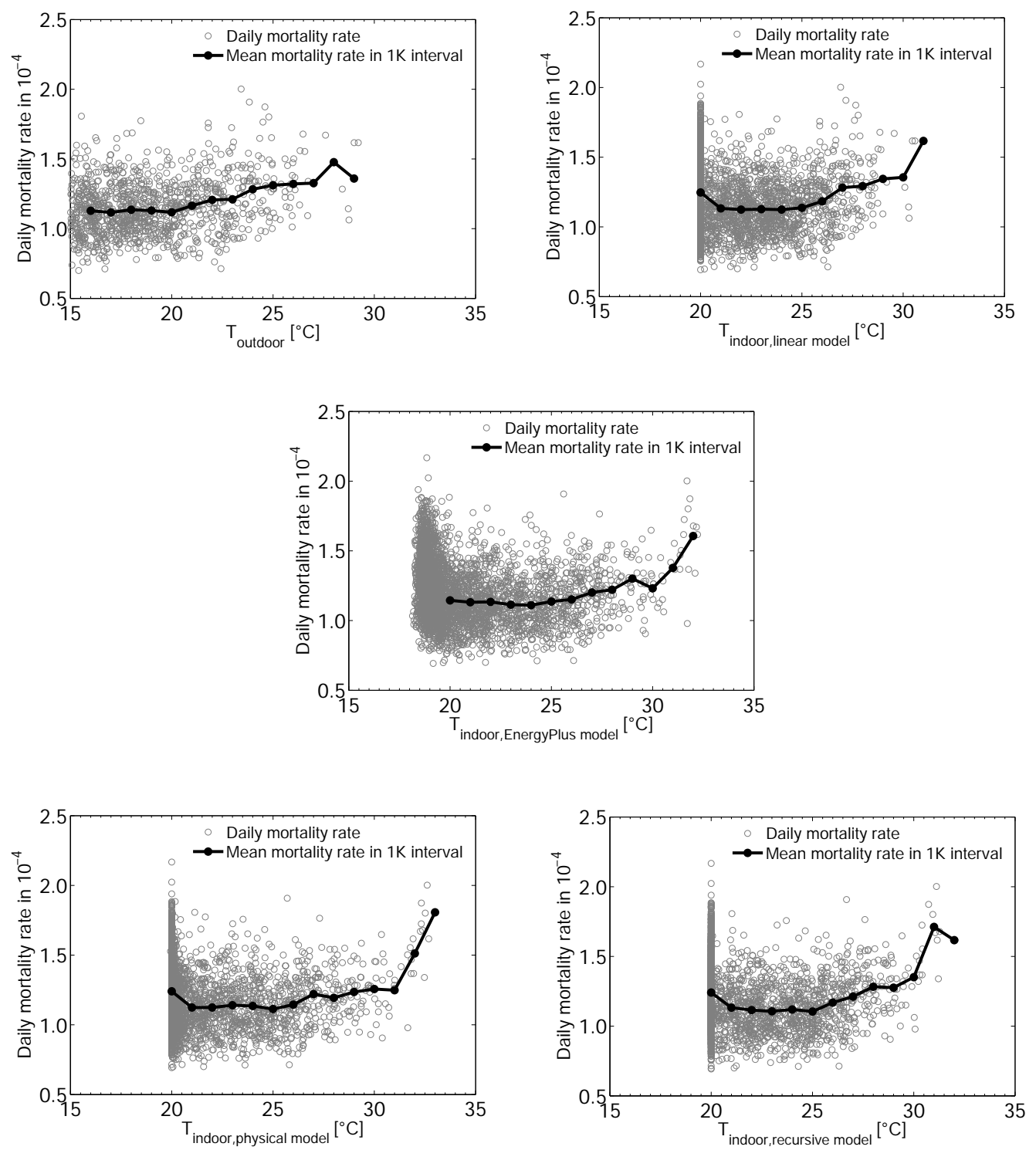

Figure 5. Mortality rate of Berlin citizens aged 65 and older in relation to measured outdoor air temperature, operative room temperature simulated with a complex building model (EnergyPlus), linear building model, physical building model, and recursive building model.

perature. Secondly, we performed a linear least-squares regression with known intercept $r_{o}$ with the heat-affected data.

Furthermore, only results of the regression analysis with high statistical significance were used for the evaluation, meaning that $p$ values obtained from a two-sided $t$-test are lower than a significance level of $0.1 \%$. We compared the coefficient of determination $R^{2}$ calculated for the heatinfluenced region of positive hazard values and the relative standard deviation of the estimated vulnerability. All results are plotted in Fig. 7 (top and middle). In addition, results of an event-based regression analysis with outdoor temperatures as described by Scherer et al. (2013) are given for comparison. The mean number of excess deaths per year is calculated using the different approaches. Note that the uncer- tainty of the number of excess deaths is calculated for a $95 \%$ confidence interval from the relative standard deviation and an assumed Gaussian distribution of the mortality rate.

The outdoor temperature approach and the indoor temperature approach based on the linear model can each explain less than $28 \%\left(R^{2}<0.28\right)$ of the variability in the mortality rates for most threshold values. The outdoor temperature approach delivers relative standard deviations of the estimated vulnerability higher than 0.15 for threshold temperatures exceeding $23^{\circ} \mathrm{C}$. The approach with temperatures calculated from the linear building model yields comparable $R^{2}$ and an elevated relative standard deviation of the estimated vulnerability exceeding 0.15 at threshold temperatures higher than $26^{\circ} \mathrm{C}$. The EnergyPlus model, the physical, and the recur- 
sive building models yield higher $R^{2}$ than the other two approaches for threshold temperatures higher than $27-28^{\circ} \mathrm{C}$. The relative standard deviation of the estimated vulnerability does not exceed 0.13 for threshold temperatures up to $29^{\circ} \mathrm{C}$. The values of excess deaths per year decrease with higher threshold temperatures for all hazard signals. Excess values are comparable for all approaches ranging from approximately 30 to 250 deaths $^{-1}$, albeit in a shifted range of threshold temperatures. Only the physical approach delivers values from 40 to 140 deaths $\mathrm{a}^{-1}$.

Considering the regression results, we see that the choice of the threshold temperature has to balance between low uncertainty and high explained variance.

\section{Discussion}

The analysis of the example data set with indoor temperatures calculated with an EnergyPlus building model, a simple physical model, and a recursive building model showed a better regression performance at comparable uncertainty than a correlation with outdoor temperatures or temperatures calculated with a linear building model. In particular, data with high excess mortality could be assigned to high indoor temperatures.

A hazard defined with indoor conditions $h_{\text {in }}$ can be interpreted as an alternative functional relation of a modified outdoor hazard $h^{\prime}$. With the physical building model (see Sect. 2.3.3) we can formulate

$h^{\prime}=h_{\text {in }}\left(T_{\text {in }}, T_{\text {in }, \mathrm{Th}}\right)=h^{\prime}\left(T_{\text {out }}, \dot{I}, \tau, \lambda, T_{\text {heat }}, T_{\text {out }, \mathrm{Th}}\right)$.

Following this interpretation, the better regression of the risk data with the hazard $h^{\prime}$ based on the physical model, in comparison to $h_{\text {out }}$ based on outdoor climate, can be explained with the additional input of the radiation data and two building parameters. However, these additional parameters have a clear physical representation and their validity should be examined in a comparative parameter analysis.

A sound scientific comparison of different risk-assessment procedures has to consider all additional parameters, for instance lag lengths and threshold temperature. The proposed climate-risk relationship operates with four physical parameters (two building parameters, exposition, and air conditioning) and two fit parameters (threshold temperature and vulnerability). Traditional concepts must use more fit parameters to account for the effects of lag, air conditioning, or buildings. Thus, the concept of using indoor hazards has implications for the definitions of heat events, acclimatization, and lag in traditional concepts.

\subsection{Heat event definition}

In this analysis, the threshold temperature used to describe the heat event is derived from the risk data. The analysis has shown that appropriate threshold temperatures for indoor and outdoor hazard must be chosen differently. The offset between outdoor and indoor threshold temperatures can be easily explained with the linear building model and the linear hazard approach, $h_{\text {in }}=c h_{\text {out }}$, as defined in the simplified indoor/outdoor risk concept (Sect. 2.2) with a hazard defined in accordance with Eq. (3):

$$
\begin{aligned}
& h_{\text {in }}=c h_{\text {out }}=c\left(T_{\text {out }}-T_{\text {out }, \mathrm{Th}}\right)=T_{\text {in }}-T_{\text {in }, \mathrm{Th}}=k_{1} T_{\text {out }} \\
& +k_{2}-k_{1} T_{\text {out }, \mathrm{Th}}-k_{2}=k_{1}\left(T_{\text {out }}-T_{\text {out }, \mathrm{Th}}\right)=k_{1} h_{\text {out }} .
\end{aligned}
$$

Therefore, we learn three important things from the linear building model: firstly, the parameter $c$ in the simplified risk concept equals the parameter $k_{1}$ of the linear building model. Thus, $c$ can be derived from measurement data or from thermal energy building simulations. Secondly, we can state that the simplified indoor/outdoor risk concept inherits the uncertainty of the linear building model. This also explains the poorer regression performance of the outdoor temperature approach. Thirdly, to compare different approaches and their threshold temperatures, the threshold values have to be transformed according to the building model. The building influence provides an explanation of the fact that studies on temperature-mortality relationships often yield low outdoor threshold temperatures. For instance, a threshold temperature of $21^{\circ} \mathrm{C}$ was derived for Berlin, Germany (Scherer et al., 2013), $16.5^{\circ} \mathrm{C}$ for the Netherlands (Huynen et al., 2001; Kunst et al., 1993), and $19^{\circ} \mathrm{C}$ for London, UK (Hajat et al., 2002) (all of these studies used daily mean air temperatures). Despite the argument that weather stations are very often situated at airports or in rural areas and therefore do not represent the urban heat island effect (Hajat and Kosatky, 2010), the elevated indoor temperatures within the building stock are a further valid explanation for low threshold temperatures in an outdoor temperature-based risk analysis.

\subsection{Lag effects}

It is well known that mortality increases after a heatwave with a lag of several days. Human physiology is often the explanation for the lag, which has a typical length on the order of 1 to 2 days (Gosling et al., 2009a; Hajat and Kosatky, 2010; Huynen et al., 2001). The building stock contributes to this lag due to thermal capacity in the building materials. However, the effect is not included in the linear building model. The EnergyPlus model, the physical model, and the recursive model include thermal capacity and as such include a lag effect. This fact contributes to the better regression performance of these models.

Comparing the recursive model, which is based on outdoor air temperatures only, and the physical model, which also includes solar radiation, there is not much difference. This highlights the importance of accounting for the general trend of the thermal lag within the building. As the simplified models used in this study were calibrated with results from the EnergyPlus simulation, the recursive model also includes 


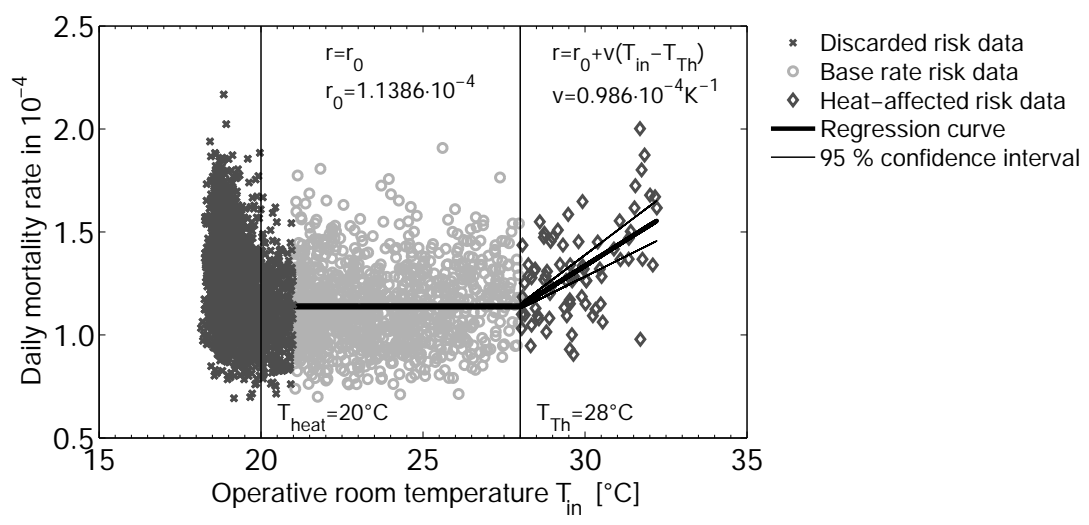

Figure 6. Mortality rate of Berlin citizens aged 65 and older in relation to operative room temperature from the EnergyPlus model and linearized risk-hazard curve according to Eq. (16) for a threshold temperature of $28^{\circ} \mathrm{C}$.

solar gains, albeit indirectly. Because this model has a similar regression performance compared to the physical model, it might be preferable for use in risk analysis studies due to its simplicity and the fact that it only requires a time series of outdoor air temperature measurements.

A separate calculation of excess deaths attributed to additional lag days is not part of this study, which might explain the low absolute number of excess deaths in comparison to other studies (e.g. Scherer et al., 2013 or Huynen et al., 2001).

\subsection{Acclimatization}

Acclimatization results from physiological and psychological adaptation, and changes in occupant behaviour and social services. However, the different contributions of these aspects can not be quantified separately and a clear differentiation between long-term adaptation and short-term acclimatization is missing yet. Some authors handle seasonal acclimatization with empirical methods by subtracting a dynamic baseline mortality which is calculated as a moving average from the time-series data. For instance, non-parametric locally weighted smoothing (Hajat et al., 2002) and moving average smoothing (Davis et al., 2003) have been used to define baseline mortality rates. Often a monthly basis is used as average duration (Dessai, 2002). The thermal capacity of buildings has a similar smoothing effect on hazard, but it is part of the causal chain from adverse outdoor heat to effective health impact. Therefore, smoothing techniques in heathealth risk analysis have to be interpreted with regard to their indirect description of thermal inertia in the built environment.

Long-term acclimatization as a form of adaptation by use of air conditioning, heat alerts, and cooling shelters, as well as by gradual physiological adaptation can be incorporated into projections by using temperature-response functions of "surrogate" cities (Gosling et al., 2009a; Knowlton et al., 2007). This method has the advantage that non-linear devel- opments influencing vulnerability can be used in the projections. However, the contributions of the underlying causes are not evaluated. By extraction of the building characteristics and air-conditioning coverage with the proposed concept, projections on the long-term acclimatization effect can be more reasonable.

\subsection{Further research}

The example calculation in this study is a proof of concept and the risk concept has to be validated with further data. In particular, risk data of populations in similar socio-economic conditions but within different building types should be analysed to evaluate the specific influence of the building typology on adverse health effects. Groups with diverse access to air conditioning should also be evaluated for further validation of the role of air conditioning in risk prevention. Furthermore, the sensitivity of regression performance on the building parameters must be evaluated to define the required quality of the building model parametrization.

It is well known that the variation of the indoor climate of specific building types is greater than the spatial variation of the outdoor temperatures in a city (e.g. Mavrogianni et al., 2012; Oikonomou et al., 2012). Therefore, information on the spatial distribution of indoor temperatures is necessary for a concise risk analysis (Taylor et al., 2015). However, the aggregation of indoor climates of different dwellings on such spatial scales requires a great deal of computational effort. The proposed physical and recursive building models can also be used to simulate indoor temperatures for a larger building stock by varying the building parameters and outdoor climate with lower computational effort. The influence of heat adaptation on the building level, which is analysed with complex building models in overheating studies (e.g. Porritt et al., 2012; Mavrogianni et al., 2012), can be fed easily into reliable projections with the simplified models serving as an interface between individual short-term building simulations and long-term risk projections. 
(a)

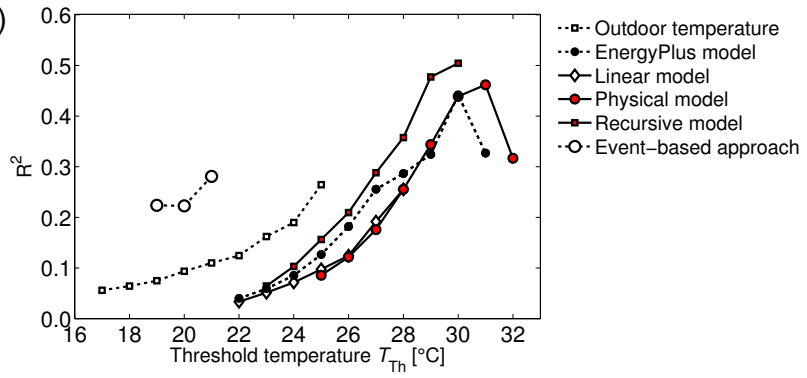

(b)

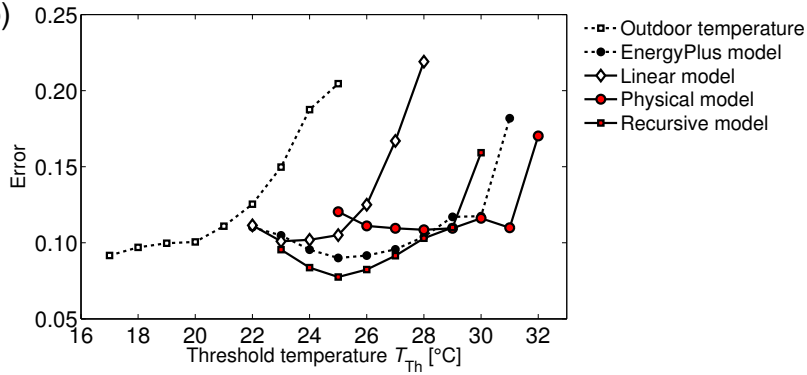

(c)

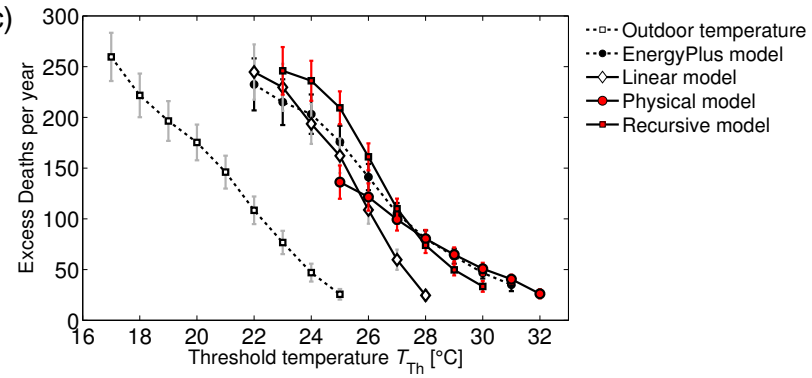

Figure 7. Coefficient of determination $R^{2}$ (top), relative standard deviation of the estimated vulnerability (middle), and calculated excess deaths (bottom) for the time-series regression analysis in dependence of threshold temperature for outdoor hazard and indoor hazard calculated with EnergyPlus, linear, physical, and recursive building models. Results of the event-based regression analysis with a significance level of $0.1 \%$ are calculated according to Scherer et al. (2013).

The review of Gosling et al. (2009a) shows that epidemiological studies operate with different hazard values, predominantly outdoor temperature values represented in terms of minimum, maximum, mean daily temperature, or the diurnal temperature range. Our study suggests that the indoor temperature is a more plausible value, and therefore it should be evaluated how the different outdoor temperature values are correlated to the indoor temperature. Differences in these correlations might explain observed differences in the risktemperature analyses. Conversely, it should be evaluated if other values of the indoor temperature signal (e.g. minimum, maximum, or diurnal temperature range) show a better regression performances with the risk data.
As can be seen in the example regression analysis, mortality rates are highly elevated for the highest indoor temperatures, which can be associated with extreme heat events. Thus, on the one hand, mitigation strategies have to be evaluated with regard to their general impact on the heat-related risk within a city. On the other hand, especially their influence on risk reduction during excessive heat must be evaluated for the indoor and outdoor environment (Buchin et al., 2015).

A log-linear increase in risk above a threshold value is used by some authors (e.g. Gasparrini et al., 2012). Scherer et al. (2013) proposed an exponential increase in mortality at an elevated heat strain quantified using an event-based approach. These non-linear approaches might also be applied to indoor hazard data. Conversely, event detection could be refined by including the indoor climate conditions.

The modelling procedure used here assumes constant building parameters. Nonetheless, during the evaluation period, a substantial part of the building structure might possibly have been refurbished (at $1 \%$ refurbishment rate $\mathrm{a}^{-1} 10 \%$ of the buildings were altered during the time span) and the representative indoor climate for the group under consideration might have changed. Therefore, a more detailed risk evaluation should take into account changing building conditions as well as specific refurbishment measures.

\section{Conclusions}

The study demonstrates the importance of considering indoor climate in heat-related risk assessment. A sound concept is proposed which includes the building as a principal hazard modifier. A key consideration has been the simplicity of the building models and a pragmatic approach to handling spatially aggregated risk and climate data sets. Furthermore, the concept is robust because it avoids a bias by parametrizing the heat event definition with the risk data.

Obviously, building models are essential in the understanding and evaluation of the indoor climate and allow for a calculation of a time series of indoor climate conditions from a time series of outdoor climate conditions. Model parametrization can be based on measurement data or on complex building simulations, as shown in this study.

We have illustrated that assuming linearity between indoor and outdoor hazard is not very accurate, but it also allows for an interpretation of exposure, air-conditioning ratio, and building influence within a traditional risk analysis. Moreover, we have shown that these effects are implicitly included in the vulnerability term in a traditional risk analysis. The inaccuracy of a linear assumption can be avoided by application of a physical or recursive building model. These simplified modelling approaches are considered to be sufficient to calculate the indoor hazard for a spatially aggregated building stock. The significantly higher accuracy of the regression 
results shows that essential causalities are included. Furthermore, the analysis shows that heat event definitions, lag, and the handling of acclimatization in existing studies should be discussed in view of the prevailing building structure. This study suggests that modelling techniques on these effects indirectly include the influence of the building stock.

The results demonstrate that better statistical explanation can be accomplished with indoor-based climate-risk relationships and we recommend that these be used in heathealth risk assessments and projections. The findings allow for a better assessment of the risk reduction potential of mitigation strategies focused on the indoor and outdoor climate. Predictions of the future development of heat-related risk are much more reliable if trends concerning climate change, urban heat island development, demography, building design, and market penetration of air-conditioning equipment can be considered separately, which could be done with the proposed concept in a plausible manner.

\section{The Supplement related to this article is available online at doi:10.5194/nhess-16-963-2016-supplement.}

Author contributions. Oliver Buchin conceived the concept, designed and implemented the building models, coded the calculation algorithms, and prepared the manuscript. Fred Meier assembled the input weather data. Britta Jänicke, Fred Meier, and Dieter Scherer gave technical and conceptual support. Felix Ziegler supervised the analysis. All authors discussed the results and implications and commented on the manuscript at all stages.

Acknowledgements. This study is funded by Deutsche Forschungsgemeinschaft (German Research Foundation) with research grant: DFG 1736 "Urban Climate and Heat Stress in midlatitude cities in view of climate change" under codes SCHE 750/8-1, SCHE 750/9-1, ZI 524/9-1. Thanks are expressed to Christoph Nytsch-Geusen and Katharina Mucha for fruitful discussions, to Hans C. Dambeck for support with the EnergyPlus software, to Nikki Byrne and Mary-Jane Radford Arrow for sharing linguistic proficiency, and to two anonymous referees for their comments on the manuscript. A substantial part of this paper was presented at the Third International Conference on Countermeasures to Urban Heat Island, 13-15 October 2014, Venice, Italy.

Edited by: B. D. Malamud

Reviewed by: two anonymous referees

\section{References}

Armstrong, B. G., Chalabi, Z., Fenn, B., Hajat, S., Kovats, S., Milojevic, A., and Wilkinson, P.: Association of mortality with high temperatures in a temperate climate: England and Wales, J. Epidemiol. Commun. H., 65, 340-345, doi:10.1136/jech.2009.093161, 2011.

Beizaee, A., Lomas, K. J., and Firth, S. K.: National survey of summertime temperatures and overheating risk in English homes, Build. Environ., 65, 1-17, 2013.

Brandt, K.: Heatwave forecasting with a coupled air-building model, in: Proceedings of 6th International Conference on Urban Climate (ICUC), University of Gothenborg/Sweden, 667670, 2006.

Brasche, S. and Bischof, W.: Daily time spent indoors in German homes-baseline data for the assessment of indoor exposure of German occupants, Int. J. Hyg. Envir. Heal., 208, 247-253, 2005.

Buchin, O., Hoelscher, M.-T., Meier, F., Nehls, T., and Ziegler, F.: Evaluation of the health-risk reduction potential of countermeasures to urban heat islands, Energ. Buildings, 2015.

Coumou, D. and Robinson, A.: Historic and future increase in the global land area affected by monthly heat extremes, Environ. Res. Lett., 8, 034018, doi:10.1088/1748-9326/8/3/034018, 2013.

Davis, R. E., Knappenberger, P. C., Michaels, P. J., and Novicoff, W. M.: Changing Heat-Related Mortality in the United States, Environ. Health Persp., 111, 1712-1718, 2003.

Dessai, S.: Heat stress and mortality in Lisbon part I. Model construction and validation, Int. J. Biometeorol., 47, 6-12, 2002.

Dessai, S.: Heat stress and mortality in Lisbon Part II. An assessment of the potential impacts of climate change, Int. J. Biometeorol., 48, 37-44, 2003.

DWD: Deutscher Wetter Dienst, Time series data of air temperature, wind speed, wind direction, relative humidity, global horizontal radiation, and normal direct radiation from 2003 to 2011 , Potsdam, Germany, http://werdis.dwd.de, last access: 1 September 2014.

EnergyPlus: EnergyPlus Engineering Reference, University of Illinois and the Ernest Orlando Lawrence Berkeley National Laboratory, online documentation, https:/energyplus.net/sites/ default/files/pdfs_v8.3.0/EngineeringReference.pdf, last access: 11 December 2015.

Erbs, D., Klein, S., and Duffie, J.: Estimation of the diffuse radiation fraction for hourly, daily and monthly-average global radiation, Sol. Energy, 28, 293-302, 1982.

Fenner, D., Meier, F., Scherer, D., and Polze, A.: Spatial and temporal air temperature variability in Berlin, Germany, during the years 2001-2010, Urban Climate, 10, Part 2, 308-331, doi:10.1016/j.uclim.2014.02.004, iCUC8: The 8th International Conference on Urban Climate and the 10th Symposium on the Urban Environment, 2014.

Field, C. B., Barros, V., Stocker, T., Qin, D., Dokken, D., Ebi, K., Mastrandrea, M., Mach, K., Plattner, G.-K., Allen, S., Tignor, M., and Midgley, P., eds.: Managing the risks of extreme events and disasters to advance climate change adaptation: Special report of the Intergovernmental Panel on Climate Change, Cambridge Univ. Press, Cambridge, http://www.ipcc-wg2. gov/SREX/images/uploads/SREX-All_FINAL.pdf (last access: 25 February 2014), 2012.

Franck, U., Krüger, M., Schwarz, N., Grossmann, K., Röder, S., and Schlink, U.: Heat stress in urban areas: Indoor and outdoor 
temperatures in different urban structure types and subjectively reported well-being during a heat wave in the city of Leipzig, Meteorol. Z., 22, 167-177, 2013.

Gabriel, K. M. and Endlicher, W. R.: Urban and rural mortality rates during heat waves in Berlin and Brandenburg, Germany, Environ. Pollut., 159, 2044-2050, 2011.

Gasparrini, A., Armstrong, B., Kovats, S., and Wilkinson, P.: The effect of high temperatures on cause-specific mortality in England and Wales, Occup. Environ. Med., 69, 56-61, 2012.

Giannaros, T. M., Melas, D., Daglis, I. A., and Keramitsoglou, I.: Development of an operational modeling system for urban heat islands: an application to Athens, Greece, Nat. Hazards Earth Syst. Sci., 14, 347-358, doi:10.5194/nhess-14-347-2014, 2014.

Gosling, S. N., Lowe, J. A., McGregor, G. R., Pelling, M., and Malamud, B. D.: Associations between elevated atmospheric temperature and human mortality: a critical review of the literature, Clim. Change, 92, 299-341, 2009a.

Gosling, S. N., McGregor, G. R., and Lowe, J. A.: Climate change and heat-related mortality in six cities Part 2: climate model evaluation and projected impacts from changes in the mean and variability of temperature with climate change, Int. J. Biometeorol., 53, 31-51, 2009b.

Guest, C., Wilson, K., Woodward, A. J., Hennessy, K., Kalkstein, L., Skinner, C., and McMichael, A. J.: Climate and mortality in Australia: retrospective study, 1979-1990, and predicted impacts in five major cities in 2030, Clim. Res., 13, 1-15, 1999.

Hajat, S. and Kosatky, T.: Heat-related mortality: a review and exploration of heterogeneity, J. Epidem. Comm. Health, 64, 753760, doi:10.1136/jech.2009.087999, 2010.

Hajat, S., Kovats, R. S. A. R., and Haines, A.: Impact of hot temperatures on death in London: a time series approach, J. Epid. Comm. Health, 56, 367-372, 2002.

Huynen, M.-M., Martens, P., Schram, D., Weijenberg, M. P., and Kunst, A. E.: The impact of heat waves and cold spells on mortality rates in the Dutch population, Environ. Health Perspect., 109, 463-470, 2001

IWU: Deutsche Gebäudetypologie. Darmstadt: Typology Approach for Building Stock Energy Assessment (TABULA) Project:, Tech. rep., Institut Wohnen und Umwelt, online documentation, http://www.building-typology.eu/downloads/public/docs/ brochure/DE_TABULA_TypologyBrochure_IWU.pdf (last access: 4 June 2014), 2011.

Jenkins, D., Patidar, S., Banfill, P., and Gibson, G.: Probabilistic climate projections with dynamic building simulation: predicting overheating in dwellings, Energ. Buildings, 43, 1723-1731, 2011.

Jenkins, P. L., Phillips, T. J., Mulberg, E. J., and Hui, S. P.: Activity patterns of Californians: use of and proximity to indoor pollutant sources, Atmos. Environ., 26, 2141-2148, 1992.

Ji, Y., Fitton, R., Swan, W., and Webster, P.: Assessing overheating of the UK existing dwellings - A case study of replica Victorian end terrace house, Build. Environ., 77, 1-11, 2014.

Kilbourne, E. M., Choi, K., Jones, T. S., and Thacker, S. B.: Risk factors for heatstroke: a case-control study, JAMA, 247, 33323336, 1982.

Knowlton, K., Lynn, B., Goldberg, R. A., Rosenzweig, C., Hogrefe, C., Rosenthal, J. K., and Kinney, P. L.: Projecting heat-related mortality impacts under a changing climate in the New York City region, Am. J. Publ. Health, 97, 2028-2034, 2007.
Krause, C. and Schulz, C.: Aufenthaltszeiten der deutschen Bevölkerung im Innenraum, im Freien, im Straßenverkehr, Umweltmed. Forsch. Prax., 3, 249, 1998.

Kunst, A. E., Looman, C. W. N., and Mackenbach, J. P.: Outdoor Air Temperature and Mortality in the Netherlands: A TimeSeries Analysis, Am. J. Epidem., 137, 331-341, 1993.

Mavrogianni, A., Wilkinson, P., Davies, M., Biddulph, P., and Oikonomou, E.: Building characteristics as determinants of propensity to high indoor summer temperatures in London dwellings, Build. Environ., 55, 117-130, 2012.

Mavrogianni, A., Davies, M., Taylor, J., Chalabi, Z., Biddulph, P., Oikonomou, E., Das, P., and Jones, B.: The impact of occupancy patterns, occupant-controlled ventilation and shading on indoor overheating risk in domestic environments, Build. Environ., 78, 183-198, 2014.

Meehl, G. A.: More Intense, More Frequent, and Longer Lasting Heat Waves in the 21st Century, Science, 305, 994-997, 2004.

Oikonomou, E., Davies, M., Mavrogianni, A., Biddulph, P., Wilkinson, P., and Kolokotroni, M.: Modelling the relative importance of the urban heat island and the thermal quality of dwellings for overheating in London, Build. Environ., 57, 223-238, 2012.

Oke, T. R.: The energetic basis of the urban heat island, Q. J. Roy. Meteorol. Soc., 108, 1-24, 1982.

O’Neill, M. S., Zanobetti, A., and Schwarz, J.: Disparities by Race in Heat-Related Mortality in Four US Cities: The Role of Air Conditioning Prevalence, J. Urban Health, 82, 191-197, 2005.

Peduzzi, P., Dao, H., Herold, C., and Mouton, F.: Assessing global exposure and vulnerability towards natural hazards: the Disaster Risk Index, Nat. Hazards Earth Syst. Sci., 9, 1149-1159, doi:10.5194/nhess-9-1149-2009, 2009.

Peng, R. D., Tebaldi, C., McDaniel, L., Bobb, J., Dominici, F., and Bell, M. D.: Toward a quantitative estimate of future heat wave mortality under global climate change, Environ. Health Persp., 119, 701-706, 2010.

Pfafferott, J. and Becker, P.: Erweiterung des Hitzewarnsystems um die Vorhersage der Wärmebelastung in Innenräumen, Bauphysik, 30, 237-243, 2008.

Porritt, S. M., Cropper, P. C., Shao, L., and Goodier, C. I.: Ranking of interventions to reduce dwelling overheating during heat waves, Energ. Buildings, 55, 16-27, 2012.

Rosenthal, J. K., Kinney, P. L., and Metzger, K. B.: Intra-urban vulnerability to heat-related mortality in New York City, 1997-2006, Health Place, 30, 45-60, doi:10.1016/j.healthplace.2014.07.014, 2014.

Salagnac, J.-L.: Lessons from the 2003 heat wave: a French perspective, Build. Res. Inform., 35, 450-457, 2007.

Scherer, D., Fehrenbach, U., Lakes, T., Lauf, S., Meier, F., and Schuster, C.: Quantification of heat-stress related mortality hazard, vulnerability and risk in Berlin, Germany, DIE ERDE - Journal of the Geographical Society of Berlin, 144, 238-259, 2013.

SDUD: Senate Department of Urban Development (SDUD): Flächennutzung und Stadtstruktur, Dokumentation der Kartiereinheiten und Aktualisierung des Datenbestandes, Edition 2010, http://www.stadtentwicklung.berlin.de (last access: 20 May 2014), 2011.

Semenza, J. C., Rubin, C. H., Falter, K. H., Selanikio, J. D., Flanders, W. D., Howe, H. L., and Wilhelm, J. L.: Heat-related deaths during the July 1995 heat wave in Chicago, New Engl. J. Med., 335, 84-90, 1996. 
Sheridan, S. C., Allen, M. J., Lee, C. C., and Kalkstein, L. S.: Future heat vulnerability in California, Part II: projecting future heatrelated mortality, Clim. Change, 115, 311-326, 2012.

SOBB: Statistical Office Berlin Brandenburg: Daily age-classified number of deaths and semi-annual population data of Berlin by age groups between 2001 and 2010, Derived from the register of residents, https://www.statistik-berlin-brandenburg.de (last access: 16 April 2014), 2013.

Taylor, J., Wilkinson, P., Davies, M., Armstrong, B., Chalabi, Z., Mavrogianni, A., Symonds, P., Oikonomou, E., and Bohnenstengel, S. I.: Mapping the effects of Urban Heat Island, housing, and age on excess heat-related mortality in London, Urban Clim., 14, 517-528, 2015.

Vandentorren, S., Bretin, P., Zeghnoun, A., Mandereau-Bruno, L., Croisier, A., Cochet, C., Riberon, J., Siberan, I., Declercq, B., and Ledrans, M.: August 2003 Heat Wave in France: Risk Factors for Death of Elderly People Living at Home, Europ. J. Publ. Health, 16, 583-591, 2006.
Wolf, T. and McGregor, G.: The development of a heat wave vulnerability index for London, United Kingdom, Weather Climate Extr., 1, 59-68, 2013.

Wright, A. J., Young, A. N., and Natarajan, S.: Dwelling temperatures and comfort during the August 2003 heat wave, Building Serv. Eng. Res. Technol., 26, 285-300, 2005.

Wu, J., Zhou, Y., Gao, Y., Fu, J. S., Johnson, B. A., Huang, C., Kim, Y.-M., and Liu, Y.: Estimation and uncertainty analysis of impacts of future heat waves on mortality in the eastern United States, Environ. Health Persp., 122, 10-16, 2014.

Zacharias, S., Koppe, C., and Mücke, H.-G.: Climate Change Effects on Heat Waves and Future Heat Wave-Associated IHD Mortality in Germany, Climate, 3, 100-117, 2014. 